The International Journal of Indian Psychology

ISSN 2348-5396 (e) | ISSN: 2349-3429 (p)

Volume 4, Issue 1, No. 83, DIP: 18.01.169/20160401

ISBN: 978-1-365-64761-1

http://www.ijip.in | October-December, 2016

\title{
Comparison of Management of Depression in Different Age Groups: A Clinical Study
}

\author{
Anil Kumar Jain ${ }^{1 *}$, Sandeep Kumar ${ }^{2}$
}

\section{ABSTRACT}

Background: Depression has been considered 4th causes of diseases worldwide according to World Health Organization (WHO). Depression requires proper diagnosis and management in different age groups. This study was conducted to evaluate the comparison of management of depression in different age groups, especially in young, middle and older age groups. Materials \& Methods: This study was conducted in department of Psychiatry in year 2010. Those who were diagnosed and obtained treatment in year 2010 were enrolled and considered for the study. It consisted of 240 patients diagnosed with depression. They were divided into 3 groups depending upon age. Group I (Young group) - <40 years, group II (Middle aged group) - 40-60 years and group III (Older group)- $>60$ years. Each group contained 80 patients each. We evaluated number and type of drugs used for antidepressant treatment, their effectiveness (psychotherapy, pharmacotherapy, combination of psychotherapy and pharmacotherapy, spontaneously remission). Results: This study comprised of 240 patients. They were divided into 3 groups depending upon age. Group I (Young group) - <40 years, group II (Middle aged group)40-60 years and group III (Older group)- >60 years. Each group contained 80 patients each. The difference was no significant $(\mathrm{P}<0.05)$. $40 \%$ of patients in group I, $45 \%$ in group II and $65 \%$ in group III were of 1 drug only. 20\% in group I, 25\% in group II and $10 \%$ in group III was on 2 drugs. $10 \%$ in group I, $15 \%$ in group II and 5\% in group III was on 3 drugs. Patients were on no drug in group I (30\%), group II (15\%) and group III (10\%). The difference was no significant $(\mathrm{P}<0.05) .40 \%$ of patients were on selective serotonin reuptake inhibitors (SSRI), $25 \%$ were on combination of selective serotonin reuptake inhibitors and benzodiazepines (BDZ) and 35\% were on benzodiazepines only. In group II, 35\% of patients were on selective serotonin reuptake inhibitors (SSRI), 40\% were on combination of selective serotonin reuptake inhibitors and benzodiazepines (BDZ) and 25\% were on benzodiazepines only. In group III, $40 \%$ of patients were on selective serotonin reuptake inhibitors (SSRI), 42\% were on combination of selective serotonin reuptake inhibitors and benzodiazepines (BDZ) and 12\% were on benzodiazepines

\footnotetext{
${ }^{1}$ Associate Professor, Dept of Psychiatry, Integral Institute of Medical Sciences and Research, Lucknow, Uttar Pradesh, India

${ }^{2}$ Associate Professor, Dept of Psychiatry, Mayo Institute of Medical Sciences, Barabanki, U.P., India

*Responding Author

(C) 2016 A Kumar, S Kumar; licensee IJIP. This is an Open Access Research distributed under the terms of the Creative Commons Attribution License (http://creativecommons.org/licenses/by/2.0), which permits unrestricted use, distribution, and reproduction in any Medium, provided the original work is properly cited.
} 


\section{Comparison of Management of Depression in Different Age Groups: A Clinical Study}

only. The difference was significant in all the groups regarding combination therapy and benzodiazepines $(\mathrm{P}<0.05)$. Type of therapy used in all groups was either general practitioner (GP) support, psychotherapy, pharmachotherapy, pharmachotherapy or GP support, combination of psychotherapy and pharmachotherapy. There was significant difference in all the groups regarding combination therapy $(\mathrm{P}<0.01)$. Conclusion: Young patients usually do not take any medication in depression. Older take more than 1 or 2 medication at same time. Young patients were more on SSRI while older were equally on SSRI and combination of SSRI \& BDZ.

Keywords: Depression, pharmachotherapy, psychotherapy

Depressive disorders are becoming common nowadays. It has high mortality and morbidity. It is a great public health problem. Depression has been considered 4th causes of diseases worldwide according to World Health Organization (WHO). Depression requires proper diagnosis and management in different age groups.

Few consider that older age it is a negative prognostic factor for the depression which leads to multiple medical, physical and psychosocial factors whose occurrence exponentially increases with age. Old age carries poor prognosis and recovery rate. But recent research says that old people can respond to antidepressants or psychotherapy and thus subsequently the rate of recovery and prognosis increase. The management of depression is very challenging especially in older where there are diminished all types of systems. However, treatment of elderly patients includes psychotherapy, pharmacotherapy and electroconvulsive therapy (ECT), similar to young adults. Psychological therapies are strongly recommended for elderly depressed patients as they are vulnerable to adverse effects and high rates of medical problems and medication use. Older adults often have better treatment compliance, lower dropout rates, and more positive responses to psychotherapy than younger patients.

Selective serotonin reuptake inhibitors (SSRI) are the first line of antidepressants. Elderly patients use more frequently older tricyclic antidepressants because of positive experiences in previous depression episodes, as well as benzodiazepines than younger depressed patients.

This study was conducted to evaluate the comparison of management of depression in different age groups, especially in young, middle and older age groups.

\section{MATERIALS \& METHODS}

This study was conducted in department of Psychiatry in year 2010. Those who were diagnosed and obtained treatment in year 2010 were enrolled and considered for the study. Record files were retrieved from the department. It consisted of 240 patients diagnosed with depression. They were divided into 3 groups depending upon age. Group I (Young group) - <40 years, group II (Middle aged group) - 40-60 years and group III (Older group) - >60 years. Each group contained 80 patients each. 


\section{Comparison of Management of Depression in Different Age Groups: A Clinical Study}

We evaluated number and type of drugs used for antidepressant treatment, their effectiveness (psychotherapy, pharmacotherapy, combination of psychotherapy and pharmacotherapy, spontaneously remission). Results thus obtained were subjected to statistical analysis. P value less than 0.05 was considered significant.

\section{RESULTS}

This study comprised of 240 patients. They were divided into 3 groups depending upon age. Group I (Young group) - $<40$ years, group II (Middle aged group)- 40-60 years and group III (Older group)- $>60$ years. Each group contained 80 patients each (Table I). The difference was no significant $(\mathrm{P}<0.05)$. Table II shows that $40 \%$ of patients in group I, $45 \%$ in group II and $65 \%$ in group III was of 1 drug only. 20\% in group I, 25\% in group II and $10 \%$ in group III was on 2 drugs. $10 \%$ in group I, $15 \%$ in group II and $5 \%$ in group III was on 3 drugs. Patients were on no drug in group I (30\%), group II (15\%) and group III (10\%). The difference was no significant $(\mathrm{P}<0.05)$.

Graph I shows that in group I, 40\% of patients were on selective serotonin reuptake inhibitors (SSRI), 25\% were on combination of selective serotonin reuptake inhibitors and benzodiazepines (BDZ) and 35\% were on benzodiazepines only. In group II, 35\% of patients were on selective serotonin reuptake inhibitors (SSRI), $40 \%$ were on combination of selective serotonin reuptake inhibitors and benzodiazepines (BDZ) and 25\% were on benzodiazepines only. In group III, $40 \%$ of patients were on selective serotonin reuptake inhibitors (SSRI), $42 \%$ were on combination of selective serotonin reuptake inhibitors and benzodiazepines (BDZ) and $12 \%$ were on benzodiazepines only. The difference was significant in all the groups regarding combination therapy and benzodiazepines $(\mathrm{P}<0.05)$. Graph II shows type of therapy used in all groups. It was either general practitioner (GP) support, psychotherapy, pharmachotherapy, pharmachotherapy or GP support, combination of psychotherapy and pharmachotherapy. There was significant difference in all the groups regarding combination therapy $(\mathrm{P}<0.01)$.

\section{DISCUSSION}

Depression is the $4^{\text {th }}$ most common disease occurring not only in older but young adults too. Considering this disease to be the health care issue, the present study was conducted in department of psychiatry to compare the type of therapy and type of drugs used in management of depression in young, middle and older age groups.

It consisted of 240 patients diagnosed with depression. They were divided into 3 groups depending upon age. Group I (Young group) - <40 years, group II (Middle aged group)- 40-60 years and group III (Older group)- $>60$ years. Each group contained 80 patients each. We compared whether patients were on 1 or more drugs. $40 \%$ of patients in group I, $45 \%$ in group II and $65 \%$ in group III were of 1 drug only. $20 \%$ in group I, $25 \%$ in group II and $10 \%$ in group III was on 2 drugs. $10 \%$ in group I, 15\% in group II and 5\% in group III was on 3 drugs. Patients were on no drug in group I (30\%), group II (15\%) and group III (10\%). Marcus in his study

(C) The International Journal of Indian Psychology, ISSN 2348-5396 (e)| ISSN: 2349-3429 (p) | 72 


\section{Comparison of Management of Depression in Different Age Groups: A Clinical Study}

found that older patients are mostly on 2 or more drugs. While young patients either on no drugs or 1 drug.

In our study, we found that we also evaluated that whether patients were on selective serotonin reuptake inhibitors (SSRI, combination of selective serotonin reuptake inhibitors and benzodiazepines (BDZ) or benzodiazepines only. The difference was significant in all the groups regarding combination therapy and benzodiazepines $(\mathrm{P}<0.05)$. In our study we found that older patients were equally on SSRI and combination of SSRI \& BDZ. Pampanolla ${ }^{6}$ in her study found similar results. While Paykel $^{7}$ found that older uses benzodiazepines more frequently as compared to SSRI because of sedative efficiency of BDZ are more as compared to SSRI.

It also evaluated type of therapy in depression patients. We found that 30\% (24) patients in young group were on no therapy while they were more on pharmacotherapy and on general practitioner. Older patients were mostly (38\%) on pharmacotherapy and psychotherapy. There was significant difference in all the groups regarding combination therapy. Our results are in agreement with the results of Jain et $\mathrm{al}^{8}$ and Robinson et $\mathrm{al}^{9}$. However, Sawada ${ }^{10}$ in his study found that young patients were on pharmacotherapy.

\section{CONCLUSIONS}

Young patients usually do not take any medication in depression. Older take more than 1 or 2 medication at same time. Young patients were more on SSRI while older were equally on SSRI and combination of SSRI \& BDZ.

\section{Acknowledgments}

The author appreciates all those who participated in the study and helped to facilitate the research process.

\section{Conflict of Interests}

The author declared no conflict of interests.

\section{REFERENCES}

Birrer RB \& Vemuri SP: Depression in later life: a diagnostic and therapeutic challenge. American Family Physician. 2004; 69: 2375-2382.

Blazer DF: Depression in late life: review and commentary. Journal of Gerontologies. 2003; 58: 249-265.

Cuijpers P, van Straten A, Warmerdam L \& Andersson G: Psychotherapy versus the combination of psychotherapy and pharmacotherapy in the treatment of depression: a meta-analysis. Depression and Anxiety 2009; 26: 279-288.

Jain A, Sandeep Verma S. Prevalence of stress and coping strategies among college students. J Adv Med Dent Scie Res 2016;4(6):95-99 


\section{Comparison of Management of Depression in Different Age Groups: A Clinical Study}

Pampallona S, Bollini P, Tibaldi G, Kupelnick B \& Munizza C: Combined pharmacotherapy and psychological treatment for depression: a systematic review. Archives of General Psychiatry 2004; 61:714-719.

Paykel ES, Brugha T \& Fryers T: Size and burden of depressive disorders in Europe. European Neuro psychopharmacology 2005; 15:411-423.

Robinson WD, Geske JA, Prest LA \&, Barnacle R: Depression treatment in primary care. Journal of the American Board of Family Practice. 2004; 18:79-86.

Sawada N, Uchida H, Suzuki T, Watanabe K, Kikuchi T, Handa T \& Kashima H: Persistence and compliance to antidepressant treatment in patients with depression: a chart review. BMC Psychiatry. 2009; 9: 38-42.

Tanno S, Ohhira M, Tsuchiya Y, Takeuchi T, Tanno S \& Okumura T: Frequent early discontinuation of SSRI prescribed by primary care physicians in young males in Japan. Internal Medicine 2009; 48:1263-1266.

Tardieu S, Bottero A, Blin P , Bohbot M, Goni S, Gerard A \& Gasquet I: Roles and practices of general practitioners and psychiatrists in management of depression in the community. BMC Family Practice. 2006; 7:5.

Table I Distribution of patients

\begin{tabular}{|c|c|c|c|}
\hline Groups & Group I & Group II & Group III \\
\hline Age range & $<40$ years & $40-60$ years & $>60$ years \\
\hline Number & 80 & 80 & 80 \\
\hline
\end{tabular}

Table II Patients on 1 or more drugs in all groups

\begin{tabular}{|c|c|c|c|}
\hline Number of drugs & Group I & Group II & Group III \\
\hline 1 & $40 \%$ & $45 \%$ & $65 \%$ \\
\hline 2 & $20 \%$ & $25 \%$ & $10 \%$ \\
\hline 3 & $10 \%$ & $15 \%$ & $5 \%$ \\
\hline No drugs & $30 \%$ & $15 \%$ & $10 \%$ \\
\hline
\end{tabular}


Graph I Types of antidepressents used by different groups

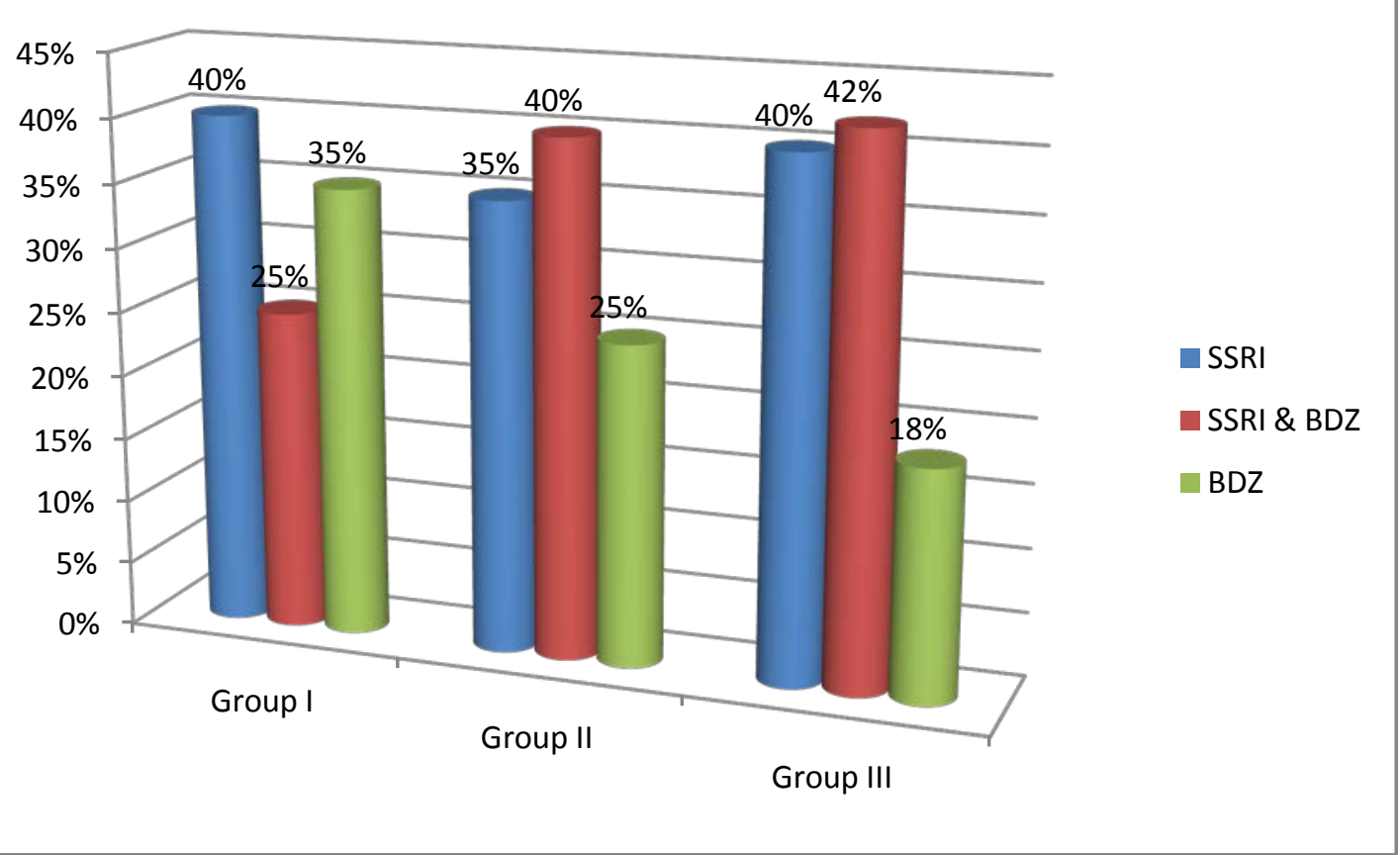

Graph II Type of therapy used in all groups

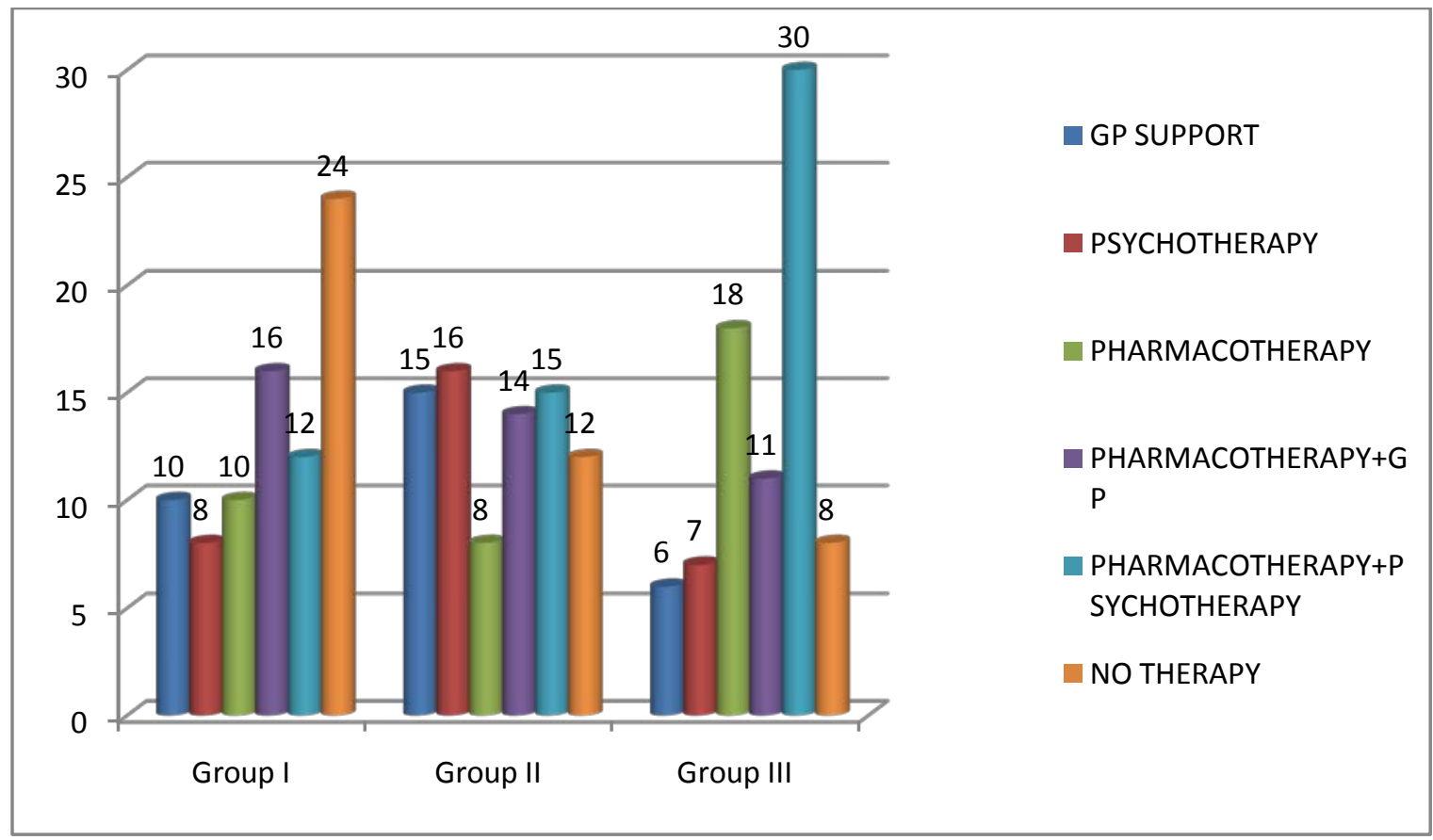

How to cite this article: A Kumar, S Kumar (2016), Comparison of Management of Depression in Different Age Groups: A Clinical Study, International Journal of Indian Psychology, Volume 4, Issue 1, No. 83, ISSN:2348-5396 (e), ISSN:2349-3429 (p), DIP:18.01.169/20160401, ISBN:978-1-365-64761-1

(C) The International Journal of Indian Psychology, ISSN 2348-5396 (e)| ISSN: 2349-3429 (p) | 75 